\title{
Assessment of Copper Status in Patients with Paroxysmal Atrial Fibrillation
}

\begin{abstract}
Keywords: Paroxysmal atrial fibrillation; Copper status; Copper levels; Ceruloplasmin

Abstract

Background: Recent research has demonstrated disturbances of copper balance in the development of cardiovascular diseases. Copper status in patients with atrial fibrillation is still unknown. Serum or plasma copper and ceruloplasmin activity are widely used laboratory indicators of copper status.

Purpose: To evaluate copper status in the early hours of paroxysma atrial fibrillation and monitor its changes after sinus rhythm restoration.

Methods: Serum copper levels and plasma oxidase activity of ceruloplasmin were measured in 33 patients with paroxysmal atrial fibrillation (17 males, 16 females, mean age 60.03 \pm 1.93 ). Indicators were measured upon hospital admission, on the $24^{\text {th }}$ hour and on the $28^{\text {th }}$ day after sinus rhythm restoration. Thirty-three control subjects were also enrolled in the study ( 17 males, 16 females, mean age $59.27 \pm 1.72$ ) and their indicators were measured only once. Copper levels and ceruloplasmin activity were quantified by atomic absorption spectrometry and colorimetric enzymatic assay respectively.
\end{abstract}

Results: Mean duration of atrial fibrillation episodes up to hospitalization was $8.64 \pm 1.03$ hours (from 2 hours up to 24 hours). Upon admission, patients' copper levels and ceruloplasmin activity were decreased compared to controls $(16.77 \pm 0.59$ vs. $18.30 \pm 0.45 \mu \mathrm{mol} / \mathrm{L}$, $\mathrm{p}<0.05 ; 0.03 \pm 0.01$ vs. $0.07 \pm 0.01 \mathrm{~A}_{530} / \mathrm{mg}$ protein, $\mathrm{p}<0.001$ respectively) 24 hours after rhythm conversion, copper was not substantially different $(17.11 \pm 0.71$ vs. $18.30 \pm 0.45 \mu \mathrm{mol} / \mathrm{L}, \mathrm{p}>0.05)$, whereas ceruloplasmin activity was diminished $\left(0.05 \pm 0.01\right.$ vs. $0.07 \pm 0.01 \quad A_{530} / \mathrm{mg}$ protein $\mathrm{p}<0.001)$. On 28th day we established significant difference in neither of the indicators $(17.61 \pm 0.48 \mathrm{vs} .18 .30 \pm 0.45 \mu \mathrm{mol} / \mathrm{L}, \mathrm{p}>0.05 ; 0.06 \pm 0.01 \mathrm{vs}$ $0.07 \pm 0.01 \mathrm{~A}_{530} / \mathrm{mg}$ protein, $\mathrm{p}>0.05$ )

Conclusion: Our results provide evidence for disturbances of copper homeostasis in patients with paroxysmal atrial fibrillation. Decreased copper levels and ceruloplasmin activity during the first hours of arrhythmia and their subsequent elevation following sinus rhythm restoration give us grounds to assume that these changes are closely related to the disease pathogenesis.

\section{Abbreviations}

\section{AF: Atrial Fibrillation; PAF: Paroxysmal Atrial Fibrillation}

\section{Introduction}

Copper is an essential for the human organism trace element whose functions are related to the development of connective tissue, nervous system, bones, antioxidant system etc., $[1,2]$. Its deficit leads to bone malformations, leucopenia, anaemia etc., $[3,4]$.

Studies carried out in recent years show the significance of this trace element for the development of a number of cardiovascular diseases. Changes have been observed in the serum level in ischemic heart disease $[5,6]$, heart failure $[7,8]$, and cardiomyopathies $[9,10]$. According to some authors, deviations in copper homeostasis are an

\section{Journal of}

\section{Cardiobiology}

Mariya Negrinova Negreva ${ }^{1 *}$, Svetoslav Jivkov Georgiev $^{2}$, Atanas Penev Penev ${ }^{1}$, Prodanova $\mathrm{K}^{1}$, Rossitsa Borisova Georgieva ${ }^{3}$, Krasimira Prodanova $^{5}$ and Albena Alexandrova Alexandrova ${ }^{4}$

${ }^{1}$ First Clinic of Cardiology, Varna University Hospital "St Marina”, Hristo Smirnenski, 1, 9000 Varna, Bulgaria ${ }^{2}$ Second Clinic of Cardiology, Varna University Hospital "St Marina”, Hristo Smirnenski, 1, 9000 Varna, Bulgaria ${ }^{3}$ National Center of Public Health and Analyses, Sofia, Bulgaria ${ }^{4}$ Laboratory of Free Radicals Processes, Institute of Neurobiology, Bulgarian Academy of Sciences, Sofia, Bulgaria

${ }^{5}$ Faculty of Applied Mathematics and Informatics, Technical

University of Sofia, Bulgaria

\section{*Address for Correspondence}

Mariya Negrinova Negreva, MD, First Clinic of Cardiology, Varna University Hospital "St Marina", Hristo Smirnenski, 1, 9000 Varna, Bulgaria, Tel: +359 888487 303; Fax: +359 52302 881; E-mail: mnegreva@abv.bg

Copyright: ( $) 2014$ Negreva MN, et al. This is an open access article distributed under the Creative Commons Attribution License, which permits unrestricted use, distribution, and reproduction in any medium, provided the original work is properly cited.

Submission: 28 April, 2014

Accepted: 06 August, 2014

Published: 11 August, 2014

Reviewed \& Approved by: Dr. Hui Huang, Associate Professor, Department of Cardiology, Sun Yat-sen Memorial Hospital, Sun Yat-sen University, P.R. China

independent risk factor for cardiovascular incidence and mortality $[11,12]$.

Despite the keen clinical and research interest in copper, searching in Science Direct, Scopus, PubMed and Google Scholar database done until February 2014 found single studies on copper status in patients with atrial fibrillation (AF), with ambiguous results presented $[13,14]$. No data were found about the copper status of such patients after sinus rhythm restoration, which would give additional grounds to seek relation with the pathogenetic mechanisms of the disease.

Disturbances of copper homeostasis could be either copper deficiency or copper overload. A commonly used laboratory indicator for evaluation of copper status is the serum or plasma levels of the element itself [15].

Another indicator of copper balance in the human organism is ceruloplasmin. It is a $\alpha_{2}$-glycoprotein in its essence binding about $95 \%$ of the total circulating copper in blood. Initially the protein is synthesized as an apoprotein in the liver and subsequently, after incorporating six or seven atoms of copper in its molecule, is secreted by the hepatocytes as a holoprotein [16,17]. Three of those atoms form the so-called 'trinuclear cluster', responsible for the protein's enzyme activity [18]. Initially described as a 'copper-carrying protein', nowadays ceruloplasmin is known to be the major multicopper oxidase in the human organism [19]. The oxidase activity of ceruloplasmin shows high sensitivity to copper levels and well characterizes copper status $[17,20]$.

\section{Aim}

To evaluate the copper status in patients with paroxysmal atrial fibrillation (PAF) (established within 48 hours) by investigating serum copper levels and plasma oxidase activity of ceruloplasmin. 
Citation: Negreva MN, Georgiev SJ, Penev AP, Prodanova K, Georgieva RB, et al. Assessment of Copper Status in Patients with Paroxysmal Atrial Fibrillation. J Cardiobiol. 2014;2(2): 5.

\section{Materials and Methods}

\section{Study population}

The study was conducted in the Intensive Cardiac Unit of Varna University Hospital for the period of October 2010 to May 2012. Subject to the investigation were patients with PAF (AF established within 48 hours). From 338 screened patients, consecutively were selected thirty-three (17 males, 16 females, mean age 60.03 \pm 1.93 ) with successful sinus rhythm restoration and lack of recurrence of the arrhythmia until the end of the study. Only patients with structurally normal hearts ${ }^{\star}$ were included in the study.

Thirty-three control subjects were also enrolled in the study (17 males, 16 females, mean age $59.27 \pm 1.72$ ), so the total number of study participants were sixty-six. Controls had structurally normal hearts ${ }^{*}$ and no history or electrocardiographic data for AF. The control group was formed as identical to the patient group in terms of the factors known to affect our study indicators of copper status, namely: sex, age (in decades), body mass index (BMI), bad habits (alcohol intake and smoking), accompanying diseases as well as treatment of accompanying diseases (anti-hypertensive, antidiabetic and lipidlowering drugs).

In patients, regularization of the rhythm was achieved in all patients by using the drug propafenone. It was administered following its treatment plan with total duration of maximum 24 hours [21,22]. After sinus rhythm restoration, until the end of the study all patients took p.o. propafenone in a maintenance dose of $150 \mathrm{mg}$ three times daily.

The onset of the AF episode was precisely determined on the basis of patient's case history, in which the beginning of arrhythmia was clearly described as a subjective feeling of "sudden onset of palpitation" continuing up to the moment of hospitalization. An electrocardiogram was performed immediately after hospitalization. The diagnosis of AF was accepted only after its confirmation by the electrocardiogram.

During the control checks electrocardiography was performed and patients were questioned for "palpitation" or similar feeling. None of the methods (anamnestic or electrocardiographic) established any recurrences of AF.

The same exclusion criteria were applied to both patients and controls (see below).

Criteria for exclusion from the study:

1. Cardiovascular diseases: ischaemic heart disease; uncontrolled hypertension; implanted device to treat rhythm conduction disorders;

2. Other diseases-renal or hepatic insufficiency; diseases of the central nervous system or endocrine system (with exclusion of type 2 diabetes, noninsulin-dependent, with good control); inflammatory and/or infectious diseases in the past three months; neoplastic, haematological or autoimmune disorders; chronic pulmonary disease;

3. Hormone replacement therapy, pregnancy, systemic administration of analgesics including NSAIDs;
4. Impossibility for the patients to clearly identify the beginning of arrhythmia.

${ }^{\star}$ For the purpose of this study as structurally healthy hearts were defined those, where on the basis of electrocardiography and echocardiography studies, no moderate or severe valvular disease [23], operated valvular defects, congenital heart disease, cardiomyopathies, inflammatory heart disease, systolic or diastolic heart failure, were identified.

\section{Study protocol}

Serum copper status and oxidase activity of plasma ceruloplasmin in the patients were studied in dynamics as blood samples were taken three times-immediately after admission to the ward (baseline values), twenty four hours and twenty eight days after sinus rhythm restoration.

In the control group the indicators were tested once.

To avoid diet influence on serum circulating levels of copper, patients followed their usual home diet after hospital discharge until the end of the study. During their stay in the department patients received no additional copper supply. No changes were done in the treatment of concomitant diseases including hypertension, diabetes mellitus and dyslipidemia. No additional drugs were applied to patients except for propafenone (to all patients).

\section{Sample processing and analysis}

Copper content was examined in the serum obtained from venous blood collected into serum vacutainer VACUETTE/4.0/Serum Sep. Ceruloplasmin oxidase activity was determined in plasma obtained from venous blood collected into heparin vacutainer VACUETTE/4.0 $\mathrm{ml} / \mathrm{Li}$ Hep. All blood samples were centrifuged at $600 \mathrm{~g}$ for $10 \mathrm{~min}$ and the separated plasma and serum were frozen at $-70{ }^{\circ} \mathrm{C}$ and preserved at this temperature for up to six months.

Serum copper levels were analysed by means of flame atomic absorption spectrometry at wavelength $324.8 \mathrm{~nm}$ and band pass $0.7 \mathrm{~nm}$. Serum samples were diluted $1+3$ with deionized water and introduced by continuous spraying into a nebulizer-burner system. The results are the average of two replicates, each with three automatic measurements; calibration is done according to a standard calibration curve [24].

Internal quality control of the copper determination was performed by analysis of certified reference material Seronorm ${ }^{\mathrm{TM}}$ Trace Elements Serum, Level 2, obtained from SERO AS, Norway.

The oxidase activity of ceruloplasmin was determined spectrophotometrically by the method of Ravin [25]. The absorption was read at $530 \mathrm{~nm}$ and the enzyme activity was expressed as $\mathrm{A}_{530} /$ mg protein.

Each plasma sample was analysed in triplicate and the obtained single results are in a good agreement $(\mathrm{p}>0.001)$.

All samples sent to the laboratory were coded, which did not allow the researchers to have access to data associated with the sample itself (control or patient, and the date of its collection).

\section{Statement}

All the authors of the manuscript declare that the study was 
Citation: Negreva MN, Georgiev SJ, Penev AP, Prodanova K, Georgieva RB, et al. Assessment of Copper Status in Patients with Paroxysmal Atrial Fibrillation. J Cardiobiol. 2014;2(2): 5.

performed in accordance with the Declaration of Helsinki for Human Researches [26] and after the approval of the Scientific Research Ethics Commission at the University Hospital St. Marina in Varna. All participants gave written informed consent to the study procedures.

\section{Statistical analysis}

Statistical analysis was performed using software product Graph Pad Prism 4. Descriptive statistics was used for the calculation of indicators of relative share, mean values and standard error of the mean (SEM). Analysis of the hypotheses was made through the $\mathrm{t}$-criterion of Student for comparing mean values. Statistical significance was established when $\mathrm{p}<0.05$. All results were presented as mean value \pm SEM.

\section{Results}

The clinical characteristics of the study group and the control group are presented in Table 1.

The patients' group did not differ from controls' group in terms of number of participants in each group, age and gender structure as well as cardiovascular risk factors $(\mathrm{p}>0.05)$.

The statistical analysis showed that mean duration of AF episodes up to hospitalization was $8.64 \pm 1.03$ (from 2 hours up to 24 hours).

Figure 1 shows that baseline values of serum copper levels were decreased compared to those of the controls ( $16.77 \pm 0.59$ vs.

Table 1: Characteristics of the patients' and control group.

\begin{tabular}{|l|c|c|c|}
\hline & Patients with PAF & Control group & P values \\
\hline $\begin{array}{l}\text { Number of participants in } \\
\text { the group }\end{array}$ & 33 & 33 & 1 \\
\hline Age (years) & $60.03 \pm 1.93$ & $59.27 \pm 1.72$ & 0.77 \\
\hline Men/Women & $17 / 16$ & $17 / 16$ & 1 \\
\hline Cardiovascular risk factors & \multicolumn{3}{|c|}{} \\
\hline Hypertension & $21(63.64 \%)$ & $24(73.73 \%)$ & 0.38 \\
\hline Diabetes mellitus type 2 & $1(3.03 \%)$ & $1(3.03 \%)$ & 1 \\
\hline Dyslipidemia & $3(9.09 \%)$ & $1(3.03 \%)$ & 0.30 \\
\hline Smoking* & $4(12.12 \%)$ & $7(21.21 \%)$ & 0.32 \\
\hline Alcohol intake & $4(12.12 \%)$ & $6(18.18 \%)$ & 0.49 \\
\hline $\begin{array}{l}\text { Body Mass Index (BMI) } \\
\text { kg/m }\end{array}$ & $23.86 \pm 0.49$ & $23.98 \pm 0.48$ & 0.86 \\
\hline Treatment of Hypertension, Diabetes mellitus type 2 and Dyslipidemia \\
\hline Beta-blockers & $8(24.24 \%)$ & $10(30.30 \%)$ & 0.58 \\
\hline $\begin{array}{l}\text { Angiotensin converting } \\
\text { enzyme inhibitor }\end{array}$ & $10(30.30 \%)$ & $7(21.21 \%)$ & 0.40 \\
\hline Sartans & $5(15.15 \%)$ & $6(18.18 \%)$ & 0.74 \\
\hline $\begin{array}{l}\text { Others (calcium channel } \\
\text { blockers or diuretics) }\end{array}$ & $8(24.24 \%)$ & $13(39.39 \%)$ & 0.19 \\
\hline Statins & $2(6.06 \%)$ & $1(3.03 \%)$ & 0.55 \\
\hline Metformin & $1(3.03 \%)$ & $1(3.03 \%)$ & 1 \\
\hline
\end{tabular}

*The smokers did not smoke more than half a packet weekly. The hospitalized patients had not smoked minimum 24-48 hours before the onset of arrhythmia The investigations of the controls and those on the $28^{\text {th }}$ day after discharge were performed after a 48-hour period free of smoking.

**No more than 1-2 drinks/weekly. The hospitalized patients had not consumed alcohol for a minimum of 48 hours before the onset of arrhythmia. The investigations of the controls and those on the $28^{\text {th }}$ day after discharge were performed after a 48-hour period without alcohol consumption

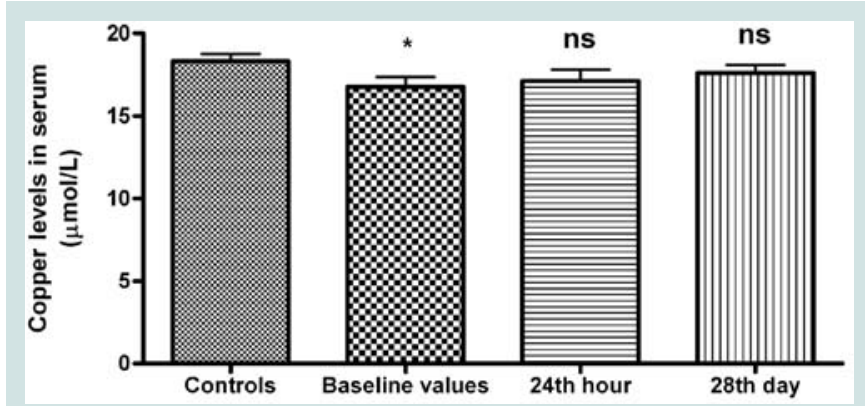

Figure 1: Dynamics in serum copper content in patients with PAF $(\mu \mathrm{mol} / \mathrm{L})$ (baseline values - values measured upon hospital admission; $24^{\text {th }}$ hour values twenty four hours after sinus rhythm restoration; $28^{\text {th }}$ day - values measured twenty eight days after sinus rhythm restoration; * $-p<0.05$;ns statistically not significant).

$18.30 \pm 0.45 \mu \mathrm{mol} / \mathrm{L}, \mathrm{p}<0.05)$. Measured twenty four hours and twenty eight days after sinus rhythm restoration, copper values of patients were not statistically different from that of the controls $(17.11 \pm 0.71$ vs. $18.30 \pm 0.45 \mu \mathrm{mol} / \mathrm{L}, \mathrm{p}>0.05 ; 17.61 \pm 0.48$ vs. $18.30 \pm 0.45 \mu \mathrm{mol} / \mathrm{L}$, $\mathrm{p}>0.05$; respectively).

Plasma oxidase activity of ceruloplasmin was lower upon patients' admission to the hospital $\left(0.03 \pm 0.01\right.$ vs. $0.07 \pm 0.01 \mathrm{~A}_{530} / \mathrm{mg}$ protein, $\mathrm{p}<0.001$ ) (Figure 2). Twenty four hours after rhythm regularization, enzyme activity was still decreased $\left(0.05 \pm 0.01\right.$ vs. $0.07 \pm 0.01 \mathrm{~A}_{530}$ ' $\mathrm{mg}$ protein, $\mathrm{p}<0.001)$, while on the twenty eighth day no significant difference was established $\left(0.06 \pm 0.01\right.$ vs. $0.07 \pm 0.01 \mathrm{~A}_{530} / \mathrm{mg}$ protein, $\mathrm{p}>0.05$ ).

\section{Discussion}

It is known that despite the relatively low copper content in the human body $(<100 \mathrm{mg})$, copper homeostasis is under tight control [27]. It is regulated through the processes of intestinal absorption and biliary excretion [28]. The liver takes central place in copper homeostasis [29]. It stores the bulk of absorbed copper and controls the processes of blood secretion and biliary elimination. Owing to good regulatory mechanisms, copper levels in the body are characterized by exceptional stability [30]. Therefore even with large variations in daily intake of copper from 0.8 to $7.5 \mathrm{mg} / \mathrm{day}$, plasma levels of the trace element remain within the norm [31].

The results of our study showed that upon patients' admission to the hospital both serum levels of copper and ceruloplasmin plasma activity were decreased (Figures 1 and 2). These one-way changes in both indicators give reason to assume that there is a disturbance in the copper balance. Copper deficiency is present in the early hours (up to the $24^{\text {th }}$ hour) of the clinical manifestation of AF. It is this fact that makes it possible to assume that the established copper imbalance is most probably closely related to the mechanisms of the disease.

It has already been established that chronic AF is characterized by decreased atrial contractility and reduction in $\mathrm{I}_{\mathrm{ca}}$ amplitudes and current densities [32]. Copper deficiency results in depressed peak shortening of the miocytes as well as intracellular calcium rise and decay. In this way copper deficiency may lead to impaired cardiomyocyte contractile function and calcium homeostasis [33]. Influencing calcium homeostasis and cellular contractility, copper may play key role in the maintenance of effective contractility. It is quite 
Citation: Negreva MN, Georgiev SJ, Penev AP, Prodanova K, Georgieva RB, et al. Assessment of Copper Status in Patients with Paroxysmal Atrial Fibrillation. J Cardiobiol. 2014;2(2): 5.

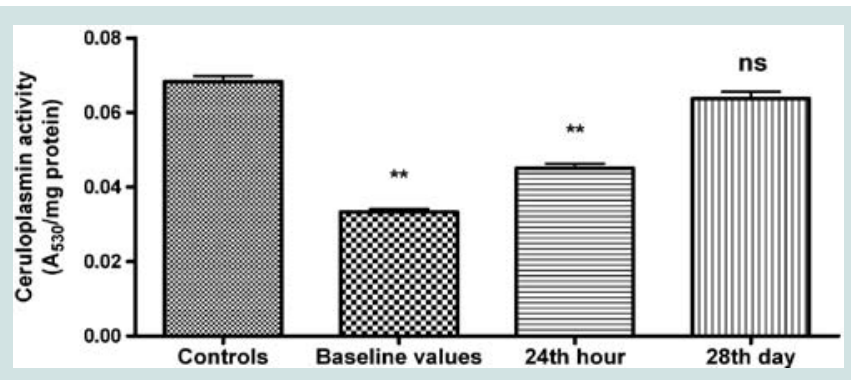

Figure 2: Dynamics in plasma oxidase activity of ceruloplasmin in patients with PAF ( $A_{530} / \mathrm{mg}$ protein). (baseline values - values measured upon hospital admission; $24^{\text {th }}$ hour - values twenty four hours after sinus rhythm restoration; $28^{\text {th }}$ day - values measured twenty eight days after sinus rhythm restoration; ${ }^{* *}$ - $p<0.001 ; n s-$ statistically not significant)

possible that copper deficiency may be closely related to mechanical extension and atrial fibrillation. Further evidence is needed to clarify this relation. It would be appropriate in future studies to investigate the effect of the administration of copper products in AF recurrences.

The results obtained 24 hours after sinus rhythm restoration did not show a statistically significant difference in copper serum levels in patients and controls. Rapid increase in copper levels most probably was due to the already described strict regulatory mechanisms of copper status which restore copper balance in case of mild copper deficiency $[27,30]$.

On the other hand, although not statistically significant, the absolute values of the $24^{\text {th }}$ hour remain in the lower borderline compared to control values $(17.11 \pm 0.71$ vs. $18.30 \pm 0.45 \mu \mathrm{mol} / \mathrm{L})$. Experimental studies have shown that lower borderline copper levels have been associated with changes in the myocardium. At sub-cellular level alterations are monitored in the number and structure of the mitochondria, and on cellular level there is significant myocyte hypertrophy with collagen deposition [15]. It appears that the structure and function of the myocardium are sensitive even to marginal copper levels. These data give rise to the need for additional studies to seek the meaning of 'normal marginal values' of copper for the clinical course of AF, including its appearance and recurrence. Despite serum copper levels did not differ from those of healthy controls, ceruloplasmin activity was still significantly reduced (Figure 2). This fact could be explained by the high sensitivity of the enzyme activity to the marginal copper levels [34], while it is a prerequisite to seek connection with the other functions that the enzyme performs.

Ceruloplasmin is known to be plasma oxidase with expressed ferroxidase activity $[19,35]$. It catalyzes the conversion of $\mathrm{Fe}^{2+}$ into $\mathrm{Fe}^{3+}$ which enables their binding to transferrin. That prevents the participation of $\mathrm{Fe}^{2+}$ in the Haber-Weiss reaction and the formation of highly reactive hydroxyl radicals, which are the main initiators of lipid peroxidation. Ceruloplasmin ferroxidase activity determines it as an important antioxidant [36]. The decrease in its activity is indicative of a breach in plasma antioxidant protection, which makes the issue of copper status and its implications for the pathogenesis of AF even more topical.

The results obtained 28 days after sinus rhythm restoration revealed that between patients and controls, there was no statistically significant difference in both the serum levels of copper and the enzyme activity of ceruloplasmin, which is evidence of recovery of copper balance. It is worth noting that the process occurs slowly over time.

Discussing our results, it is appropriate to note that copper status is closely related to nutritional status and that serum copper levels could be influenced by dietary copper intake. The fact raises the question whether decreased copper levels in patients with PAF were result of copper deficiency in the food. In this sense we should emphasize that during the whole period of the study none of the subjects changed his customary diet. This gives us ground to assume that changes in copper levels are unlikely to be a diet consequence. Most probably they result from impaired regulation of copper balance that may be involved in AF mechanisms.

In conclusion, we could say that the clinical manifestation of PAF is associated with changes in copper status. Copper deficiency is observed, which is transient and restores by the $28^{\text {th }}$ day after rhythm regularization. Development of copper imbalance in the early hours of atrial fibrillation ( $24^{\text {th }}$ hour of arrhythmia onset) is an important argument in favour of the assumption that copper is involved in the mechanisms associated with the initiation of the rhythm disorder.

\section{References}

1. Osredkar J, Sustar N (2011) Copper and zinc, biological role and significance of copper/zinc imbalance. J Clinic Toxicol S: 3.

2. Iakovidis I, Delimaris I, Piperakis SM (2011) Copper and its complexes in medicine: A biochemical approach. Mol Biol Int.

3. Fraga CG (2005) Relevance, essentiality and toxicity of trace elements in human health. Mol Aspects Med 26: 235-244.

4. Bügel S, Harper A, Rock E, O'Connor JM, Bonham MP, et al. (2005) Effect of copper supplementation on indices of copper status and certain CVD risk markers in young healthy women. Br J Nutr 94: 231-236.

5. Ford ES (2000) Serum copper concentration and coronary heart disease among US adults. Am J Epidemiol 151: 1182-1188.

6. Bayir A, Kara H, Kiyici A, Oztürk B, Akyürek F (2013) Levels of selenium, zinc, copper, and cardiac troponin I in serum of patients with acute coronary syndrome. Biol Trace Elem Res 154: 352-356.

7. Ghaemian A, Salehifar E, Shokrzadeh M (2010) Zinc and copper in different types of heart failure. Trace Elem Electrolytes 27: 57.

8. Alselevany BK, Hassan SA, Abdul-Aziz AA (2008) Evaluation of serum copper status in patients with chronic heart failure. Dohuk Med J 2: 31-40.

9. Shokrzadeh M, Ghaemian A, Salehifar E, Aliakbari S, Saravi SS, et al. (2009) Serum zinc and copper levels in ischemic cardiomyopathy. Biol Trace Elem Res 127: 116-123.

10. Salehifar E, Shokrzadeh M, Ghaemian A, Aliakbari S, Saeedi Saravi SS (2008) The study of $\mathrm{Cu}$ and $\mathrm{Zn}$ serum levels in idiopathic dilated cardiomyopathy (IDCMP) patients and its comparison with healthy volunteers. Biol Trace Elem Res 125: 97-108.

11. Engström G, Hedblad B, Tydén P, Lindgärde F (2009) Inflammation-sensitive plasma proteins are associated with increased incidence of heart failure: $a$ population-based cohort study. Atherosclerosis 202: 617-622.

12. Leone N, Courbon D, Ducimetiere P, Zureik M (2006) Zinc, copper, and magnesium and risks for all-cause, cancer, and cardiovascular mortality. Epidemiology 17: 308-314.

13. Ghaemian A1, Salehifar E, Jalalian R, Ghasemi F, Azizi S, et al. (2011) Zinc and copper levels in severe heart failure and the effects of atrial fibrillation on the zinc and copper status. Biol Trace Elem Res 143: 1239-1246.

14. Yan YQ, Zou LJ (2012) Relation between zinc, copper, and magnesium 
Citation: Negreva MN, Georgiev SJ, Penev AP, Prodanova K, Georgieva RB, et al. Assessment of Copper Status in Patients with Paroxysmal Atrial Fibrillation. J Cardiobiol. 2014;2(2): 5.

concentrations following cardiopulmonary bypass and postoperative atria fibrillation in patients undergoing coronary artery bypass grafting. Biol Trace Elem Res 148: 148-153.

15. Li Y, Wang L, Schuschke DA, Zhou Z, Saari JT, et al. (2005) Marginal dietary copper restriction induces cardiomyopathy in rats. J Nutr 135: 2130-2136.

16. Sato M, Gitlin JD (1991) Mechanism of copper incorporation during the biosynthesis of human ceruloplasmin. J Biol Chem 266: 5128-5134.

17. Gaware V, Kotade K, Dhamak K, Somawanshi S (2010) Ceruloplasmin its role and significance: a review. Int J Biol Res 1: 153-162.

18. Xu X, Pin S, Gathinji M, Fuchs R, Harris ZL (1998) Aceruloplasminemia: an inherited neurodegenerative disease with impairment of iron homeostasis. Ann N Y Acad Sci 1012: 299-305

19. Musci G (2001) Cerulolasmin, the unique multi-copper oxidase of vertebrates. Protein Peptide Lett 8: 159-169.

20. Capo CR, Arciello M, Squitti R, Cassetta E, Rossini PM et al. (2008) Features of ceruloplasmin in the cerebrospinal fluid of Alzheimer's disease patients. Biometals 21: 367-372.

21. Bellandi F, Cantini F, Pedone T, Palchetti R, Bamoshmoosh M, et al. (1995) Effectiveness of intravenous propafenone for conversion of recent-onse atrial fibrillation: a placebo controlled study. Clin Cardiol 18: 631-634.

22. Bianconi L, Mennuni M (1998) Comparison between propafenone and digoxin administered intravenously to patients with acute atrial fibrillation. PAFIT-3 Investigators. The Propafenone in Atrial Fibrillation Italian Trial. Am J Cardio 82: $584-588$

23. Joint Task Force on the Management of Valvular Heart Disease of the European Society of Cardiology (ESC), European Association for CardioThoracic Surgery (EACTS), Vahanian A, Alfieri O, Andreotti F, et al. (2012) Guidelines on the management of valvular heart disease (version 2012). Eur Heart J 33: 2451-2496.

24. Tzatchev KN (1994) Rationalization of the trace element study in clinical laboratory. D.Sc. Thesis, Medical Academy, Sofia.

25. Ravin HA (1961) An improved colorimetric enzymatic assay of ceruloplasmin. J Lab Clin Med 55: 161-168.
26. (2008) World Medical Association Declaration of Helsinki - Ethical principles for medical research involving human subjects. 59 ${ }^{\text {th }}$ WMA General Assembly, Seoul, Republic of Korea.

27. de Romaña DL, Olivares M, Uauy R, Araya M (2011) Risks and benefits of copper in light of new insights of copper homeostasis. J Trace Elem Med Biol 25: 3-13.

28. Mercer JF, Llanos RM (2003) Molecular and cellular aspects of copper transport in developing mammals. J Nutr 133: 1481S-1484S.

29. Wijmenga C, Klomp LW (2004) Molecular regulation of copper excretion in the liver. Proc Nutr Soc 63: 31-39.

30. Turnlund JR (1998) Human whole-body copper metabolism. Am J Clin Nutr 67: $960 \mathrm{~S}-964 \mathrm{~S}$

31. Turnlund JR, Keen CL, Smith RG (1990) Copper status and urinary and salivary copper in young men at three levels of dietary copper. Am J Clin Nutr 5: 658-664.

32. Van Wagoner DR, Pond AL, Lamorgese M, Rossie SS, McCarthy PM, et al (1999) Atrial L-type $\mathrm{Ca}^{2+}$ currents and human atrial fibrillation. Circ Res 85: 428-436.

33. Relling DP, Esberg LB, Johnson WT, Murphy EJ, Carlson EC, et al. (2007) Dietary interaction of high fat and marginal copper deficiency on cardiac contractile function. Obesity (Silver Spring) 15: 1242-1257.

34. Louro MO, Cocho JA, Tutor JC (2001) Assessment of copper status in pregnancy by means of determining the specific oxidase activity of ceruloplasmin. Clin Chim Acta 312: 123-127.

35. Prohaska JR, Broderius M (2006) Plasma peptidylglycine alpha-amidating monooxygenase (PAM) and ceruloplasmin are affected by age and copper status in rats and mice. Comp Biochem Physiol B Biochem Mol Biol 143: 360366.

36. Tapryal N, Mukhopadhyay C, Das D, Fox PL, Mukhopadhyay CK (2009) Reactive oxygen species regulate ceruloplasmin by a novel mRNA decay mechanism involving its 3'-untranslated region: implications in neurodegenerative diseases. J Biol Chem 284: 1873-1883. 